\title{
Designing Rice for the $22^{\text {nd }}$ Century: Towards a Rice with an Enhanced Productivity and Efficient Photosynthetic Pathway
}

\author{
Rabin Thapa ${ }^{1, a, *}$, Nabin Bhusal ${ }^{2, b}$ \\ ${ }^{1}$ Agriculture and Forestry University, Nepal \\ ${ }^{2}$ Faculty of Agriculture, Department of Genetics and Plant Breeding, Agriculture and Forestry University, Rampur, Chitwan, Nepal
} *Corresponding author

\section{A R T I C L E I N F O A B S T R A C T}

Review Article

Rice (Oryza sativa L.) has been cultivated as an important cereal crop for more than 9,000 years and more than half of the world's population depend on rice as it is their primary source of energy. Almost $30 \%$ of the current world cereal production is represented by the rice alone. It is estimated that the world's population will reach 9.1 billion by 2050 i.e. 34 percent higher than today and for

Received : 22/08/2020

Accepted : 19/11/2020 ensuring an ample amount of food and nutrition to such large population, global consumption of cereals will need to increase from 2.6 to 2.9 billion tonnes by 2027 . On the other hand, the impacts of climate change in agriculture are expected to be negative, threatening the global food security. Besides, agriculture and global food security will be severely affected due to the COVID-19 pandemics as its after-effects are yet to be ascertained. The world needs an introduction of a new "Green revolution" in agriculture to increase crop production for food security and biofuel, because conventional breeding method have not brought much of gains not keeping its pace with the world population growth. Hence, the current study was done to review the various ongoing approaches and possible ways of designing a rice with enhanced productivity and photosynthetic capacity. One of the ways to increase yields, photosynthetic capacity accompanied by an increased Water Use Efficiency (WUE) and Nutrient Use Efficiency could be to introduce C4 traits into rice. Besides, genetic engineering using CRISPR-Cas9, molecular breeding, developing ideotype, heterosis breeding, developing apomictic rice, nitrogen fixing rice, use of nanotechnology as well as precision farming are the probable future approaches for designing a rice with high productivity. However, there are challenges and limitations in developing such rice and further research in this matter could help us get closer to developing the future rice.

\begin{tabular}{|c|c|}
\hline $\begin{array}{l}\text { Keywords: } \\
\text { Green revolution } \\
\text { C4 Rice } \\
\text { COVID-19 } \\
\text { Food security } \\
\text { CRISPR-Cas } 9\end{array}$ & $\begin{array}{l}\text { "Green revolution" in agriculture to increase crop production for food security and biofuel, because } \\
\text { conventional breeding method have not brought much of gains not keeping its pace with the world } \\
\text { population growth. Hence, the current study was done to review the various ongoing approaches } \\
\text { and possible ways of designing a rice with enhanced productivity and photosynthetic capacity. One } \\
\text { of the ways to increase yields, photosynthetic capacity accompanied by an increased Water Use } \\
\text { Efficiency (WUE) and Nutrient Use Efficiency could be to introduce C4 traits into rice. Besides, } \\
\text { genetic engineering using CRISPR-Cas9, molecular breeding, developing ideotype, heterosis } \\
\text { breeding, developing apomictic rice, nitrogen fixing rice, use of nanotechnology as well as precision } \\
\text { farming are the probable future approaches for designing a rice with high productivity. However, } \\
\text { there are challenges and limitations in developing such rice and further research in this matter could } \\
\text { help us get closer to developing the future rice. }\end{array}$ \\
\hline
\end{tabular}

\section{Introduction}

Rice (Oryza sativa L.) is the staple food for almost half the people on world with global production of $782 \mathrm{mt}$ (FAO, 2018). Rice has been cultivated as an important cereal crop for more than 9,000 years and more than half of the world's population depend on rice as it is their primary source of energy (Molina et al., 2011) while almost 30\% of the current world cereal production is represented by the rice alone. It has doubled in the last 30 years, probably with the introduction of new varieties, but its present growth barely goes along with consumption. The number of people that rely on rice for their daily nourishment will reach 4.6 billion by the year 2025, while the consumption of rice around the globe seems to be rising in last ten years (Figure 1). A new surge in production is therefore anticipated (Gnanamanickam, 2009; FAOSTAT, 2018).
The renowned Green revolution (1960s) led to an enhanced yield of rice from less than 1.5-ton $\mathrm{ha}^{-1}$ (Jennings, 1964) to the recent rice yield potential of 15-16ton ha-1 (Long-ping, 2014). Albeit success has been achieved by modern agriculture in increasing food production, it has also resulted in environmental degradation. Taking an example, the growing use of fertilizers has led to the quality degradation of aquatic sources in many regions (Foley et al., 2005). The burning issue of climate change on the other hand has been of major concern as Nelson et al. (2009), mention that although few positive results are expected in some regions of the world for some crops, as a whole the impacts of climate change on the agriculture are expected to become negative, threatening the global food security. It has been estimated that the world's population will reach 9.1 billion by 2050 
(Figure 2) i.e., 34 percent higher than today and for ensuring an ample amount of food and nutrition to such large population, global consumption of cereals will need to increase from 2.6 billion tonnes to 2.9 billion tonnes by 2027. Although there is a need of an enhanced cereal crop production, it is pretty absurd that globally the rate of growth in yields of the major cereal crops has been steadily abating as it is projected that net imports of cereals in developing countries' will more than double from 135 million metric tonnes in 2008/09 to 300 million in 2050 (FAO, 2009; FAO, 2018).

The post COVID-19 situation could rather be of a greater concern for the world. "The recent COVID-19 pandemic resulted from the emergence of a disease caused by severe acute respiratory syndrome coronavirus 2 (SARS-CoV-2)" (Henry, 2020). Agriculture and global food security will be severely affected due to the pandemics while the results will be complex (Torero, 2020), and many of the after-effects are yet to be ascertained and comprehended (Jambor et al., 2020). Despite growing reserved of cereals (FAO, 2020) it has been estimated that the number of people facing a food crisis will grow from 135 million to 265 million by the end of 2020 (Anthem, 2020).

The world needs an introduction of a new "Green revolution" in agriculture to increase crop production for food security and biofuel, because conventional breeding method have not brought much of gains not keeping its pace with the world population growth (Sowjanya et al., 2019). The future is threatened by the after-effects of COVID-19 in agriculture, impacts of climate change, increasing population and the burning issue of food security. In this limelight, this study was done to understand the possible ways for addressing the major issues i.e., by assessing the possible ways of designing a rice with enhanced productivity and efficient photosynthetic pathway, to feed the future generation.

\section{Materials and Methods}

This review has been made consulting relevant research papers and various reports. Collected information was arranged and findings from them haven been summarized and presented in texts, tables, and figures under different headings.

\section{Global Rice Consumption}

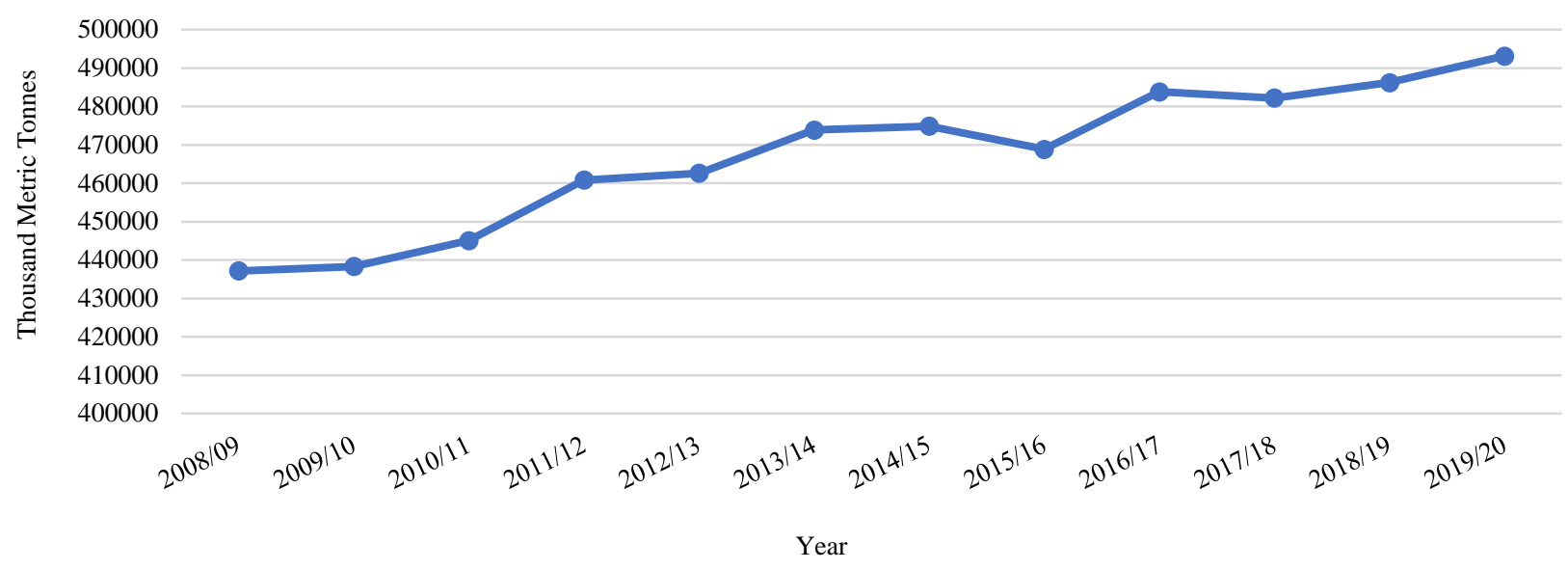

Figure 1. Global consumption pattern of rice in last ten years

12000000

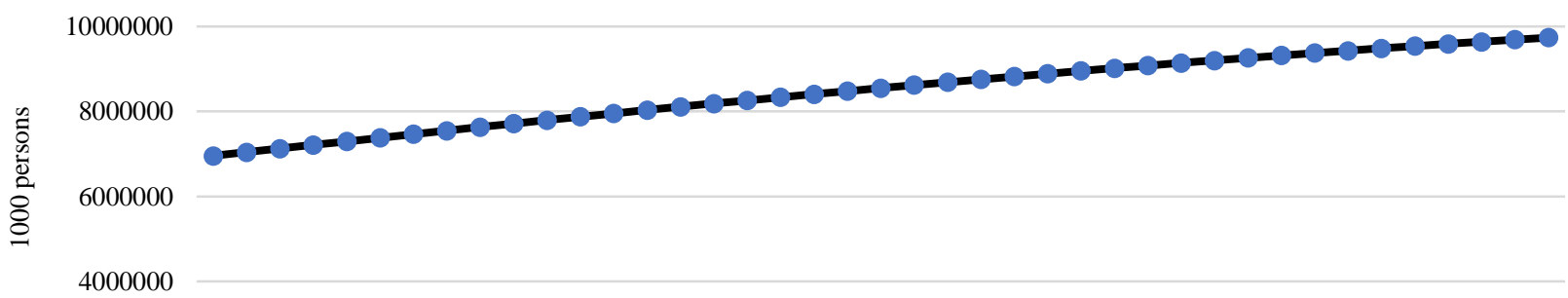

2000000

0

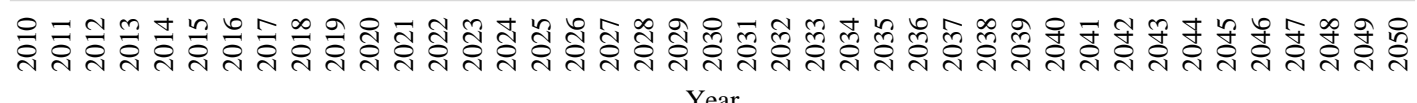

Figure 2. World total annual population projection 


\section{Thrust Areas for Improvement of Rice Productivity}

Since the ingenuous revolution brought by Norman Borlaug in the 1960s produced an enhanced yield of our major cereal crops, we have seen a steady drop in their annual yield growth. The genetic potential of the yield components viz harvests index and grain number, which were brought to limelight in the "green revolution" and subsequently by plant(cereal) breeders have largely been enhanced in our two macro cereal crops, rice and wheat. Despite the use of improved varieties and introduction of new technologies, the yield potential of rice cultivars at present has not improved significantly specifying the yield ceiling that these varieties have hit. As the growing population and climate change are putting an increased pressure on the global food supply, it is important that we continue improving crop performance, thereby grain productivity to suffice needs of increasing population (Akita, 1994; Furbank et al., 2015). The inputs of rice viz land, labor, water and fertilizer determine the production of rice significantly and these inputs will create a hurdle in increasing the rice production. Land for cultivation is fixed and hence the future gains in production of rice can be expected from an enhanced production per unit of land but not from increased area of cultivation. Similarly, with entry into the $21^{\text {st }}$ century, demand of water has increased, not only from the agricultural sectors but also from industrial sectors and household purposes while the cost for establishment of irrigation system is escalating quickly. This implies the future rice production need to be attained from limited use of water. Urbanization and deviation from agriculture to more attractive jobs imply unavailability of labor in near future. The adoption of labor efficient technologies on the other hand may take way more time for adoption and most farmers do not fancy such economically less attractive techniques. The decreasing cost of fertilizers can be assessed in the world and hence increased yields through higher application of fertilizers, especially nitrogen in farmer's field will require the introduction of new varieties. Thus, if rice can be converted into a $\mathrm{C} 4$ plant, this would then open new doors for creation of such new varieties that will give maximum production per unit land and utilize less amount of water but gives significantly high yield i.e., high-water use efficiency. Such conversion will not only address the issues of increasing population, climate change, food security but also help to alleviate poverty with zero hunger which are major goals of SDG 2030 (Dawe, 2000; UNDP, 2015).

Thus, one of the ways to increase yields accompanied by an increased Water Use Efficiency (WUE) and Nutrient Use Efficiency (NUE) could be to introduce C4 traits into C3 plants (rice). This idea came into its existence after it was proposed in the late 1990's when transgenic experiments to broaden the knowledge regarding $\mathrm{C} 4$ gene function were initiated (Matsuoka et al., 2001). A prospective solution, therefore, is to introduce an efficient photosynthetic mechanism; the $\mathrm{C} 4$ pathway into rice. This is also the proposed goal of researchers in the international C4 Rice Consortium: to recognize and concoct the genes necessary to introduce $\mathrm{C} 4$ photosynthesis in rice (Hibberd et al., 2008). The thrust area, besides involving the improvement of photosynthetic capacity, should also be aimed for these (ICAR, 2013):
- Designation, development and ultimately testing the new plant types, next generation rice and hybrid rice that will opt for an enhanced yield potential.

- Identification of genes and their deployment for enhanced efficiency of inputs we use accompanied by a marked tolerance to various abiotic and biotic stresses.

- Development of a control strategy via proper understanding the pest genomes for evolution of a biotype, the survival of rice in off-season and molecular level host-pathogen/parasite interaction.

- Development of rice varieties which are nutrition rich (Vitamin A, Vitamin E, Zinc, Iron and protein) and which are climate resilient in varied rice ecologies.

- Developing a nutrient dense rice, resource use efficient rice, nitrogen-fixing rice, apomictic rice accompanied by exploitation of microbial resources, resource conservation technologies, use of nano-tech and precision farming.

\section{Improving the Photosynthetic Capacity and Efficiency of Rice}

\section{Understanding the C3 and C4 pathways}

The recent model explaining the process of $\mathrm{C} 4$ evolution which has been widely accepted, explains a stepwise series of changes leading to the evolution of $\mathrm{C} 4$ plants from $\mathrm{C} 3$ plants (Figure. 3). The changes seen here in each of the steps leads to a rather unique evolutionary advantage for the resulting species irrespective of whether it leads to the complete expression of the $\mathrm{C} 4$ like character. This consequence explains why the evolution of the complicated trait could occur multiple times in an independent way. The model explained here is in fact based on the relative analysis of the $\mathrm{C} 3, \mathrm{C} 4$ and the $\mathrm{C} 3-\mathrm{C} 4$ intermediates and an elaborative explanation can be assessed from Sage (2004) and Gowik and Westhoff (2011).

The enzyme Ribulose-1,5-biphosphate carboxylase oxygenase (Rubisco) is the enzyme associated with assimilation of $\mathrm{CO}_{2}$ into a 3-carbon compound in case of the $\mathrm{C} 3$ plants like rice. The name, oxygenase at the end of the Rubisco suggests that besides the role of $\mathrm{CO}_{2}$ assimilation, it also catalyzes the oxidation of Ribulose1,5-bisphosphate (RuBP).

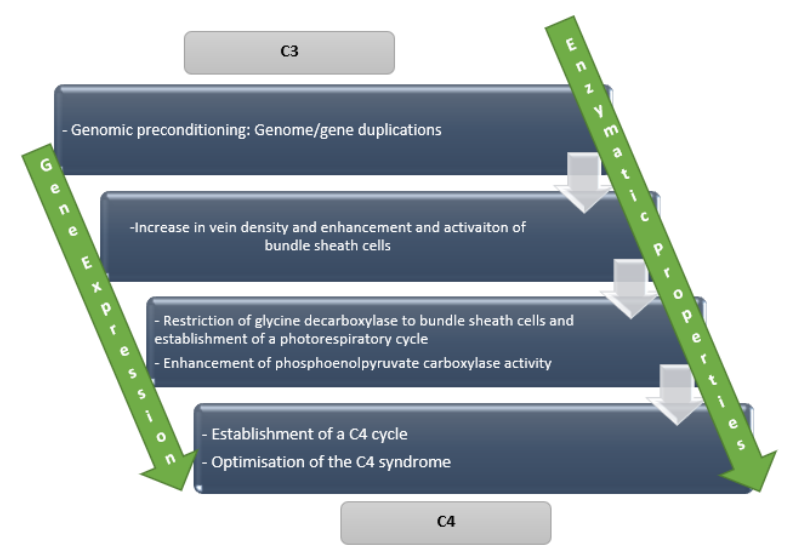

Figure 3. Evolution of C4 photosynthesis (a stepwise approach).

Note: A stepwise approach for evolution of $\mathrm{C} 4$ photosynthesis. Adapted from "The Path from C3 to C4 Photosynthesis." By Gowik, U., and Westhoff, P. 2011, American Society of Plant Biologists, 110, p.1104. 
The oxidation activity is in fact a wasteful activity referred to as photorespiration which can lead to a loss up to $25 \%$ of the carbon that was fixed already (Sage, 2004). This implies that the primary enzyme associated with fixation of $\mathrm{CO}_{2}$ in rice is in fact a poor catalyst of $\mathrm{CO}_{2}$ at existing circumstances in the atmosphere. The poor nature can be explained by the fact that this enzyme has confusing nature with respect to the selection of substrate i.e., a mere abundance of $\mathrm{O}_{2}$ is accompanied by oxygenase of Rubisco and a poor turnover rate of only one or two fixations per second when $\mathrm{CO}_{2}$ is major substrate. Unlike rice, many organisms including the cyanobacteria, algae and even some land plants have been found to develop an active mechanism involving $\mathrm{CO}_{2}$ concentration in order to overcome the inefficient process of photorespiration (Badger et al., 2011). In the course of evolution, the $\mathrm{C} 4$ photosynthesis was developed which takes place in different specialized tissue of leaves, the bundle sheath cells. What makes it distinct from the $\mathrm{C} 3$ crops is, the $\mathrm{CO}_{2}$ concentrating mechanism in the bundle sheath cells, thereby inhibiting the oxygenase action associated with the Rubisco. This means the distinctness lies in the efficiency of operation with respect to $\mathrm{CO}_{2}$ fixation i.e., operation of the Rubisco at an optimal rate. This also explains why the $\mathrm{C} 4$ crops (sorghum and maize) have better yields accompanied by an increased nitrogen use as well as water use compared to that of $\mathrm{C} 3$ crops (like rice) (Borlaug, 2007; Hibberd et al., 2008). The evolutionary process explained above could be a probable explanation as to how the oxygenase activity of the enzyme could be a remnant of history considering its evolvement 3 billion years ago. Later, it was rather impossible to revert the enzyme's action regarding oxygenase activity or replace the enzyme by another carboxylase. Nonetheless, plants acclimatized with this problem by evolving different mechanisms the best of which can be considered the $\mathrm{C} 4$ photosynthesis(Gowik \& Westhoff, 2011).

\section{Current Photosynthetic Capacity of Rice in Comparison with C4 Cereals}

It is evident that, the action of oxygenase part of Rubisco (central role in Calvin cycle), which can't be avoided, makes photosynthesis in rice an inefficient one (Legwood, 2013). Unlike rice, inside the mesophyll cells of C4 cereals, Rubisco formation is impeded and there is production of oxaloacetate followed by malate or aspartate when the bicarbonate ion $\left(\mathrm{HCO}_{3}^{-}\right)$is fixed by the enzyme Phosphoenolpyruvate Carboxylase (PEPC) inside the mesophyll cells. The three possible mechanisms involved can be NADP-ME (Nicotinamide Adenine Dinucleotide Phosphate-dependent malic enzyme), PCK or NAD-ME (Nicotinamide Adenine Dinucleotide-dependent malic enzyme) that carryout the role of decarboxylation when the $\mathrm{C} 4$-acids are diffused into bundle sheath cells which obviously have a low level of $\mathrm{CO}_{2}$ thereby exalting the $\mathrm{CO}_{2}$ level around the Rubisco to about five times more than ambient air (Furbank, 2011). In contrary, the C3 plants like rice have $\mathrm{CO}_{2}$ levels nearly half of ambient air concentrations in the chloroplast as the hindrances arise during diffusion due to stomata and mesophyll cells (Figure. 4). Thus, the photorespiration is efficiently prevented by this mechanism of concentrating $\mathrm{CO}_{2}$ in bundle sheath cells thereby inactivating oxygenase activity and making $\mathrm{C} 4$ cereals more productive than rice. (Caemmerer and Evans, 2010; Peterhansel and Maurino, 2011; Evans, 2013).

The physiology of rice is affected by higher temperature in case of rice cultivated areas $\left(>30^{\circ} \mathrm{C}\right)$ in the tropics which is its typical range, the rate of oxygenation has a sudden upsurge reducing the photosynthetic efficiency by upto $40 \%$ (Ehleringer \& Monson, 1993). This results in an inefficient photosynthesis of rice in the tropics and warm temperate regions. The potential of $\mathrm{C} 4$ crops to reduce photorespiration, thrive hot, arid environments due to an enhanced $\mathrm{CO}_{2}$ concentrating mechanism of leaves envisages a possible strategy to embark with crop improvement (Figure. 5). If the very system is introduced in the rice, besides an increased photosynthetic efficiency, an efficient utilization of scarce resources like water, fertilizer (Nitrogenous) and land can be ascertained ultimately leading to increased yield (Hibberd et al., 2008). A more obvious explanation of the efficiency of $\mathrm{C} 4$ plants can be explained by the quantity of water required for production of $1 \mathrm{~g}$ of biomass i.e., $650-800 \mathrm{~g}$ of water is required by $\mathrm{C} 3$ plants unlike $\mathrm{C} 4$ plants which do well with just 250-350g of water (Ehleringer \& Monson, 1993). The C4 plants have thus enhanced their photosynthesis unlike C3 plants even an enhanced radiation use efficiency as depicted in the Figure 5 below, although in the same ecology (Rizal et al., 1999).



Figure 4. A comparison between light response curves of a C4 plant (sorghum) and C3 plant (Rice, IR72) 


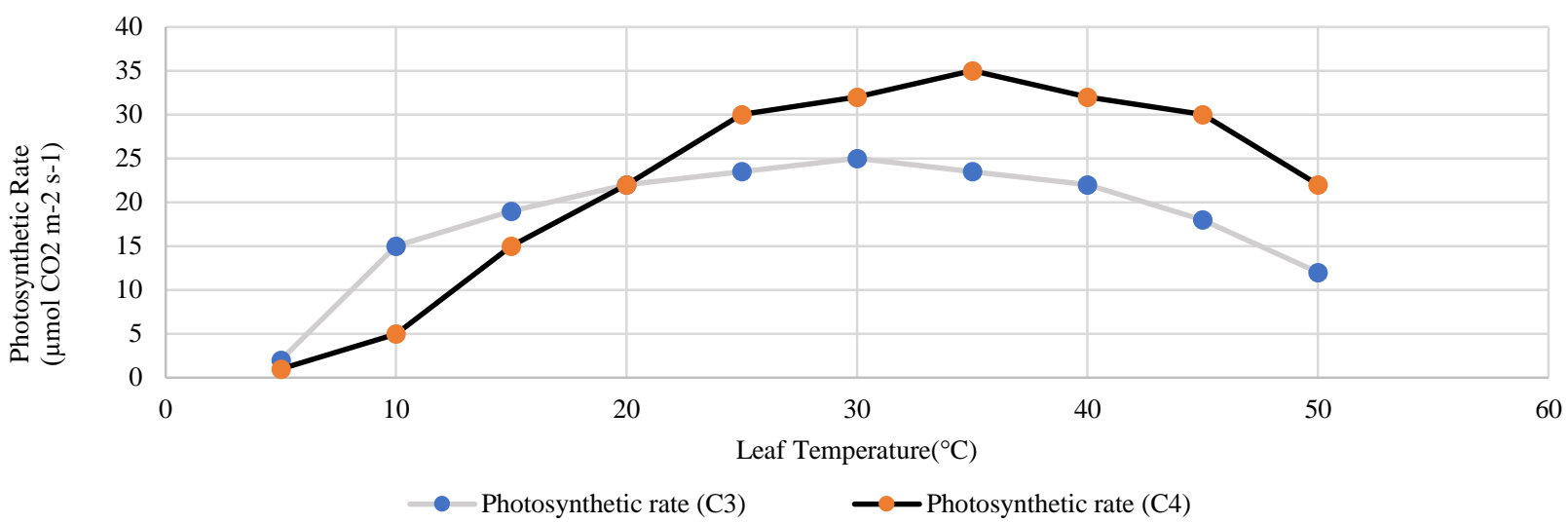

Figure 5. Typical temperature response of photosynthesis in $\mathrm{C} 3$ and $\mathrm{C} 4$ plants

Can Productivity Be Increased with an Enhanced Photosynthetic Pathway?

When trying to design high-yielding rice plants, several questions arise like; to what extent does photosynthesis shape yield? Sheehy and Mitchell (2013) proposed that breeders should aim for an advanced type of rice, different from the traditional or semi dwarf or new plant type (NPT) varieties currently available. In contrast, the $\mathrm{C} 4$ syndrome could increase yields by about $40 \%$ above the yields of semi dwarf cultivars in the tropics and by about $24 \%$ above the predicted yields for $\mathrm{C} 3$ rice in the subtropics. Experimental evidence indicates that improving photosynthetic capacity can lead to yield improvement (Long et al., 2015).

The $\mathrm{CO}_{2}$ accumulating nature of $\mathrm{C} 4$ plants opts for an efficient photosynthesis accompanied by efficient use of nitrogen, water and also the radiation which are subsequently translated into higher yields in crops. Yield potential depends mainly upon four factors viz (1) amount of total solar radiation accumulated over the growth period (2) how efficiently is the photosynthetically active radiation (PAR) intercepted (3) how efficiently the PAR is transformed to dry matter or in another words, the radiation use efficiency and (4) the resources supplied to grain or the harvest index. The harvest index of crops and accumulation of PAR were the two major issues that were addressed by the Green Revolution but the extension of growth period is rather a trivial matter as management practices of crop is limited within the weather circumstances that limit the production within a stipulated time. The one thing that matters now is the resource use efficiency (RUE) as the primary source for genetic improvement bearing high significance. Theoretically the RUE of C3 crops can be enhanced by nearly about $50 \%$ if $\mathrm{C} 4$ photosynthesis is brought under action. This insists us to convert rice from $\mathrm{C} 3$ to $\mathrm{C} 4$ in order to mitigate the global food crisis (Mitchell and Sheehy, 2008; Zhu et al., 2010; Reynolds et al., 2011). With the engineering of $\mathrm{C} 4$ pathway, raising a question regarding how economic would it be, is rather obvious. It has been reckoned that the benefit-cost ratio of using a rice with $\mathrm{C} 4$ pathway is nearly the same as that of using dwarf cultivars that were introduced during the first green revolution which brought benefits to millions of people mostly in the poor regions of the globe. This leaves us with the opinion that no other evolutionary process persists that could be attributed to $\mathrm{C} 3$ rice which could ascertain yield as well as benefit (IRRI, 2012). Primary data show that two types of transgenic rice viz PEPC and PPDK transgenic rice have shown upto $20 \%$ and $35 \%$ increase in grain yield compared to other nontransgenic plants under field conditions which was the result of increased number of tillers. Overall, the results explain why $\mathrm{C} 4$ rice has a huge potential for increment in the yield, photosynthetic ability and stress tolerance (Maurice et al., 2007).

\section{Does the Sink in Rice Bear Space Enough for C4 Productivity?}

Clear inspection of the potentiality and capacity of rice is inevitable before installation of a new photosynthetic pathway. We are aware of the enhanced productivity of $\mathrm{C} 4$ cereals, but having been acquainted with such huge productivity, the existence of equivalent size of sink is also felt inevitable. The research by Sheehy et al. (2001), put a light on this matter where they showed that the capacity of rice for production of spikelets ( $>100,000$ per sq.m) is more than twice the number of grains finally obtained at maturity ( $<50,000$ per sq.m) (Table 1$)$. The increment of yield by $30 \%$ in rice could be explained due to the enhanced photosynthesis for 33 days before heading, $\mathrm{CO}_{2}$ enrichment being the obvious reason (Yoshida, 1973). These experiments direct their findings towards the same direction i.e., another $50 \%$ of the juvenile spikelets have the potentiality to be converted into grains in the rice with C4 photosynthetic pathway i.e., sink is enough for C4 productivity.

Table 1. Mean number of spikelets at different stages and thousand grain weight in crops of IR72

\begin{tabular}{l|c}
\hline \multicolumn{1}{c|}{ Items } & $\begin{array}{c}\text { Mean } \\
\text { Number }\end{array}$ \\
\hline Number of spikelets per sq.m (Juvenile stage) & 113,848 \\
Number of spikelets per sq.m (Maturity) & 51,372 \\
Filled number of spikelets per sq.m (Maturity) & 38,793 \\
Thousand-Grain Weight (g; Moisture Content =14\%) & 24.0 \\
\hline
\end{tabular}

Note: Mean number of spikelets at different stages and Thousand Grain Weight in crops of IR72. Adapted from "Spikelet numbers, sink size and potential yield in rice." By Sheehy, J., Dionora, M., and Mitchell, P., 2001, Field Crops Research, 71, p. 77-85

\section{Designing a C4 Rice}

With the discovery of a new photosynthetic pathway i.e., C4 in the 1960's, accompanied by consciousness of the fact that $\mathrm{C} 4$ is photosynthetically efficient than $\mathrm{C} 3$, there have been raised interests regarding the potential effect of photorespiration, carbon utilization, activity of RuBisCO and eco-physiological relation of $\mathrm{C} 3$ and $\mathrm{C} 4$ plants (Hatch et al., 1971). The discovery of a novel photosynthetic 
pathway created an everlasting interest in increasing the plant yield in recent decades with more concern on feeding the increasing hungry mouths. It can be asserted that population increment has served as provocation to such research while efficiency of $\mathrm{C} 4$ plants has suggested an ensuring path to assist in the achievement of enhanced yields (Burris \& Black, 1976). Attempts have been made in the past to transfer the improvements of $\mathrm{C} 4$ photosynthetic pathway viz reduced photorespiration, enhanced use of nitrogen and water accompanied by increased efficiency of light use into C3 plants using the science of breeding. Although the method seems promising but due to the independent inheritance of genes referring to such characteristics of $\mathrm{C} 4$ plant like the Kranz anatomy, the compensation point of $\mathrm{CO}_{2}$ and increased PEPC indicated it was not a good path to follow (Bjorkman et al., 1971; Bjorkam, 1976). The most promising research for engineering $\mathrm{C} 4$ photosynthesis is being led by the $\mathrm{C} 4$ Rice Consortium under International Rice Research Institute (IRRI, Philippines). Various projects viz. physiological phenotyping, identification of rice mutants with Kranz anatomy i.e., screening is underway to develop a $\mathrm{C} 4$ rice (Covshoff et al., 2012).

\section{Concerns in Improving Photosynthetic Capacity of Rice}

Many crops which have been domesticated, just like rice, fall within such a genus that belong to clades where only $\mathrm{C} 3$ species can be found. The sophisticated pathway of $\mathrm{C} 4$ plants increase the difficulty and make their integration into C3 leaves more challenging (Sage et al., 2011). It is arguable that the genomes of such species and the $\mathrm{C} 4$ photosynthesis are incompatible. The Kranz anatomy is integral part of C4 photosynthesis and this leaf anatomy is fundamental for such photosynthetic pathway but the genes associated with such leaf anatomy have not been identified. Also, the genes governing leaf characters like thickening of bundle sheath cells, the plasmodesmatal linkage between bundle sheath and mesophyll cells including the dimorphic chloroplast features have not been characterized yet (Kajala et al., 2011) There are still many gaps in our knowhows of C4 plants and these gaps need to be filled. The identification of transporters which are clearly associated with fluxes in the metabolism as well as the regulators and loci have not been identified yet. Cellular mechanisms and specialization of anatomy of
C4 plants still need to be identified that makes C4 plant unique. What has been achieved till now by genetic engineering has not been able to address the installation of the C4 pathway and on the other hand, the challenge of engineering C4 system will further aggravate as we are acquainted with a greater number of genes associated with $\mathrm{C} 4$. For the overall realization of the $\mathrm{CO}_{2}$ fixation like that of $\mathrm{C} 4$ further challenges will arise and to address the challenge we need to realize the potential of installation in C3 plants like rice. Thus, there is a need to enhance our knowledge regarding how Rubisco can be generated and the performance of Rubisco under varied conditions viz temperature. The sustainability and maintenance of such system in C3 leaves via appropriate bioengineering is inevitable if the chloroplast system metabolism is to be facilitated (Sharwood et al., 2016). The accumulation of challenges regarding maintenance of a stable system of Rubisco is due to inability to maintain a progeny with transformed chloroplast that is heritable and also stable in none of the species of monocots (Khan \& Maliga, 1999). However, Caemmerer et al. (2012) report that, in another 15 years of experiment, they will be able to enhance the phenotype and the $\mathrm{C} 4$ rice will be able to be cultivated in farmers' field.

To convert the rice, a C3 plant into $\mathrm{C} 4$ plant the following elements need to be brought to concern (Gangurde et al., 2016):

- Concentration of $\mathrm{CO}_{2}$ in a compartment around the RUBISCO.

- $\mathrm{CO}_{2}$ fixation system which is basically light driven.

- $\quad$ Supply of ATP for regeneration of PEP.

- A pool of metabolites and compounds for regeneration of PEP; the compounds being involved in transfer to mesophyll cells from bundle sheath cells at high capacity.

- Installation of decarboxylation enzymes for release of $\mathrm{CO}_{2}$ from intermediate metabolite pool.

- Prevent leakage of $\mathrm{CO}_{2}$ from bundle sheath and maintain ratio of mesophyll to bundle sheath cells $(1: 1)$.

The roadmap to the development of a $\mathrm{C} 4$ rice by IRRI is presented Table 2 .

Table 2. Roadmap to the development of C4 Rice by IRRI and our projection

\begin{tabular}{|c|c|c|c|c|}
\hline Phases & Commercial pathway of C4 Rice & $\begin{array}{c}\text { Initial } \\
\text { Time-frame } \\
\text { (IRRI, } \\
\text { 2012) }\end{array}$ & $\begin{array}{l}\text { Tentative time-frame } \\
\quad \text { (Sage, 2004) }\end{array}$ & $\begin{array}{c}\text { Our } \\
\text { Estimates }\end{array}$ \\
\hline Phase-I & $\begin{array}{l}\text { Gene discovery and molecular toolbox, and } \\
\text { characterize regulatory controls }\end{array}$ & $2009-2011$ & 2009-2011 & 2009-2011 \\
\hline Phase-II & $\begin{array}{c}\text { Transform rice to express Kranz anatomy } \\
\text { and the } \mathrm{C} 4 \text { metabolic enzyme }\end{array}$ & $2012-2014$ & $2012-2015$ & $2012-2015$ \\
\hline Phase-III & Optimize $\mathrm{C} 4$ function in transgenic rice & $2015-2019$ & 2016-2020 & 2016-2022 \\
\hline Phase-IV & $\begin{array}{c}\text { Breed C4 from transgenic into local } \\
\text { varieties }\end{array}$ & $2020-2023$ & $2021-2025$ & $2023-2028$ \\
\hline $\begin{array}{l}\text { Product prototype development } \\
\text { (Phase I-IV) (years) }\end{array}$ & & 15 & 17 & 20 \\
\hline Post-development (years) & & & 5 & 7 \\
\hline Commercialization & & & 2030 & 2035 \\
\hline
\end{tabular}




\section{Searching for C4-ness in Wild Rice}

The best way to introduce C4-ness in the rice would be to find the genes for $\mathrm{C} 4$-ness in the wild varieties of rice. With a diverse genus and 24 species of genus Oryza only; only 2 species of which are cultivated ones while the rest belong to wild ones. The IRRI has collection of germplasm having more than 6,000 of wild rice accessions (IRRI, 2012). Although a detail study of the wild varieties needs to be done, the past study has shown some promising results in wild rice where characteristics of $\mathrm{C} 3-\mathrm{C} 4$ intermediates have been reported (Table 3). One of the most promising result can be observed where some accessions of species rufipogon exhibited a compensation point of $30 \mu \mathrm{mol} \mathrm{mol}{ }^{-1}$ and the


most inefficient process in $\mathrm{C} 3$ i.e., photorespiration was found $25 \%$ lower in rufipogon species than the sativa species. Rice spikelets have exhibited some C4 characteristics while the lemmas carried out mainly $\mathrm{C} 3$ photosynthesis accompanied by $\mathrm{CO}_{2}$ fixation using PEPC however, Kranz anatomy couldn't be found. The number of veins, total number of bundle sheath cells, number of chloroplasts in small veins were also found higher in some wild varieties of rice which need to be further screened (Vaughan, 1994; Yeo et al., 1994; Imaizumi et al., 1997; Sheehy et al., 2007).

Table 3. Percentage of bundle sheath cells (BSC) and BSC with chloroplasts in small vascular bundles

\begin{tabular}{l|ccc}
\hline Species & Source & $\begin{array}{c}\text { Bundle Sheath Cells with Chloroplasts } \\
(\%)\end{array}$ & Chloroplast area in Bundle Sheath Cells (\%) \\
\hline C4 & Our collection & 100 & $>80$ \\
C3 & Cultivated rice & 100 & 21 \\
& Oryza sativa (IR64) & & 52 \\
& Some Wild Varieties of Rice & 50 & 41 \\
& O. alta & 88 & 41 \\
& O. australiensis & 64 & 48 \\
& O. barthii & 100 & 50 \\
\hline
\end{tabular}

Note: Percentage of bundle sheath cells (BSC), BSC with chloroplasts in small vascular bundles determined via confocal microscopy. Adapted from "How the rice crop works and why it needs a new engine?" By Sheehy, J., Ferrer, A., Mitchell, P., Elmido-Mabilangan, A., Pablico, P., and Dionora, M. (2007). in J. Sheehy, P. Mitchell, and B. Hardy, Charting New Pathways to C4 Rice (pp. 3-26)

\section{Introducing Genes of C4 Photosynthesis into Rice}

The identification of genes followed by their transfer and ultimately their expression in plants has been the source of breakthrough in the field of genetics. Talking about rice, the genomic sequence was completely identified in 2005 which then provided a new working environment under functional genomics to understand the trait expression better. With recent advancements, the phenotypes can be assessed at plant level while the interaction of alleles can be assessed at system level of plants. Identification of genes which associated with a particular phenotype using the whole genome sequencing approach, even in case of mutated genes has further opened door for limitless possibilities. (Furbank et al., 2009; Zhu et al., 2010; Wang et al., 2011).

The use of Agrobacterium mediated gene transfer is most common for gene transformation and (Agarie et al., 1998; Ku et al., 1999) have claimed the transformation of two rice varieties (Japonica) viz Nipponbare and Kitaake. The genes were transformed with 3 maize genes obviously providing $\mathrm{C} 4$ characteristics to the rice. One of the major approaches, besides gene transformation is the expression of appropriate genes like those associated with PEPC, PPDK and NADP-ME enzymes. Immunolocalization studies have exhibited that PEPC was only expressed in the cytosol whereas the other two enzymes were expressed in chloroplast which was pretty obvious. These enzymes are prevalent in $\mathrm{C} 4$ cereals, especially maize and are known to remain functional in transgenic rice plants. What makes it more insightful is that the activity of these enzymes showed positive correlation with protein amount from the enzymes ( $\mathrm{Ku}$ et al., 1999). Studies suggest that the regulatory mechanism has been observed in transgenic rice plants for the activity of the enzymes present in maize responsible for $\mathrm{C} 4$ characters. The organ-specific expression of such genes is absent in $\mathrm{C} 3$ rice but can be exhibited in transgenic rice (Maurice et al., 2007). Besides maize, recently the halophyte Suaeda aralocaspica have been recognized to perform a complete $\mathrm{C} 4$ photosynthesis within the individual cells (SCC4) which is in contrast with typical C4 crops. Presented the genome sequence of the SCC4 plant which can be highly useful for understanding the evolution of such photosynthesis and in fact capable of contributing towards establishment of a $\mathrm{C} 4$ mechanism. It is expected that genes present in C3 species can be reengineered into cell-specific activities in the $\mathrm{C} 4$ pathway without any changes into their gene sequence. These results suggest the chances that only few parts of the $\mathrm{C} 4$ pathway might be recruited in rice for other parts to fall into place (ICAR, 2013; Wang et al., 2019). Xu (2016) have provided some promising results where they used CRISPR/Cas-9 mediated multiplex genome editing system for mutation of 3 major genes that negatively regulated the grain weight of rice. They concluded that the system used is highly efficient with respect to the mutagenesis frequency and can be used for rapid generation and pyramiding of beneficial alleles. The system can avoid the involvement of non-targeted genomic fragments, increasing the efficiency of breeding by allowing to select QTLs of interest thereby aiding for the pyramiding of necessary genes accompanied by multiplex gene editing. Such advancements in breeding with the help of CRISPR/Cas-9 complex can definitely to aid the transfer of genes and genome editing for engineering a $\mathrm{C} 4$ rice. 
Introduction of Efficient Rubisco, $\mathrm{CO}_{2}$ Concentration Mechanism and Lowered Photorespiration

Rubisco plays the role of central enzyme in photosynthesis and hence making it work harder is inevitable if we opt for greatly reducing the photorespiration. This can be done by increasing the concentration of $\mathrm{CO}_{2}$ around Rubisco which subsequently is associated with light saturated rate of photosynthesis. We should aim for a continuous gain in fixed carbon by creating a primitive atmosphere conditions for Rubisco i.e., an enhanced concentration of $\mathrm{CO}_{2}$ around it. The experiments carried out by scientists in past support this theory as enhanced concentrations of $\mathrm{CO}_{2}$ have been found to increase photosynthesis in rice. The major aim of engineering a $\mathrm{C} 4$ rice is to make the in-situ $\mathrm{CO}_{2}$ available for itself by rice, the concentration in $\mathrm{C} 4$ plants being 3-8 times higher.

When it comes to increasing the concentration of $\mathrm{CO}_{2}$, we should know the essentials of concentrating $\mathrm{CO}_{2}$ mechanism. If we aim for making the bundle sheath cells of C3 plants by increasing chloroplast number, introducing the necessary enzymes in the mesophyll and bundle sheath cells, it would still not be sufficing for initiation of $\mathrm{C} 4$ photosynthesis as we would still lack a proper communication among the cells. This means, we have to look for alternatives viz introduction of carboxysomes and pyrenoids into C3 plants (chloroplasts) or we could shift the location of photorespiration to bundle sheath cells which is evident in $\mathrm{C} 3-\mathrm{C} 4$ intermediate plants. We could also look for a proper alternative like, a better performing rubisco evidently from algae (a rhodophyte) or we could learn a new mechanism involved in Suaeda aralocaspica for carrying out C4 photosynthesis independently. (Whitney et al., 2001; Winzer et al., 2001; Leegood, 2002; Wang et al., 2019). However, the chance of leakage of CO2 is equally high which will squander our activities related to an efficient Rubisco. Long et al. (2006) have provided some suggestions regarding a faster regeneration of RuBP to increase rates of light-saturated photosynthesis. Raines (2006) emphasize on the possible improvements that could be brought by enhancing the heat stable nature of Rubisco activase at temperature more than 30 degrees or use of enzyme from cyanobacteria for concentration of inorganic carbon, whose precise function, once known, could be of utter significance.

\section{Change in Morphology: Reduced Vein Spacing and Increasing the Vein Density}

For an efficient $\mathrm{C} 4$ photosynthesis, besides the role of enzymes, there might be the necessity of some essential features viz a high leaf vein density and reduced vein spacing. C4 plants are reported to have such features making them a foundation trait for evolvement of $\mathrm{C} 4$ crops. The rapid exchange of photosynthates is permitted due to the amount and position of mesophyll cells and bundle sheath cells in the leaves. It implies that, if we opt for an efficient exchange of photosynthates then it is radical to introduce such features to rice. Feldman et al. (2014) carried out screening of mutant population of rice viz a deletion mutant library (cv. IR 64) and a T-DNA insertion mutant library (cv. Tainung 67) having 12,470 and 10,830 lines respectively. It was done to test for increase in leaf vein density and positive results were seen in case of 8 lines where a significant increment was reported for leaf vein density. This experiment provided a lead on other findings that leaf width could also be looked for as a phenotypic marker for finding alterations in vain density accompanied by its use for speeding up vein density related screenings. Having been aware that vein density has been hypothesized as a foundational element in evolution of $\mathrm{C} 4$ from $\mathrm{C} 3$ photosynthesis, using the increased vein density in rice as an acceptor lines is highly relevant (McKown and Dengler, 2009; Kajala et al., 2011).

\section{Other Potential Strategies Vis a Vis Yield Improvement}

\section{Genetic Engineering and Molecular Breeding}

Rice genome sequencing was successfully completed in the year 2005 and after this the interest among researchers for understanding the functional genomics is ever-increasing. First of all, it is a pre-requisite to understand the traits followed by their manipulation. Genetic engineering can be highly useful for yield improvement as we can use the functional genomics, transcriptomics, proteomics and metabolomics. Protocol for transformation of rice is established providing with an opportunity to introduce genes which modify the yield related processes. Starch is the basic biosynthesized reserve which is governed by series of enzymatic steps. The limitation in storage of starch is found due to allosteric inhibition of enzymes (in the sinks). Thus, transformation should be aimed to affect the production of starch in the sinks with regulation of the enzyme by regulating expression of appropriate genes (Kishore, 1994). Similarly, genetic engineering can be useful for improving crop yields by slowing down the senescence process via introduction of "stay-green" traits in rice. In some genotype of rice, stay-green traits are accompanied by slower degradation of Rubisco which results in accumulation of photosynthates for a longer period i.e., an enhanced canopy photosynthesis and bumper yield (Khush, 2000).

Yield is a polygenically inherited character and is under the influence of environment. The assessment of genotypes from phenotypic expression should also look forwards for low heritability. With recent advancements, quantitative trait loci (QTL) have been identified for the different phenotypic expression among different populations. The use of QTL analysis is found to be more efficient for identification of genomic regions responsible for the expression of particular traits. For the development of rice with defined characters, we must identify, validate and finally combine QTLs/regions which govern traits either individually or in group (Tanksley et al., 1989). QTLs from diverse genetic sources from different landraces, wild genotypes and varied domain shall be identified and transferred into a single genotype using restriction fragment length polymorphism (RFLP), random amplified polymorphic DNAs (RAPDs) and microsatellites. Selection for yield can be done by using molecular markers that are closely linked (Tanksley et al., 1989; ICAR, 2013; Khush, 2000). These recent developments, can be used mainly for the development of saturated molecular map. The use of linkage analysis and molecular markers the location of such QTLs can be determined. Even more useful, is the use of CRISPR-Cass9 for revealing the gene function as well as for RNA guided gene editing. Besides 
identification of QTLs CRISPR/Cass9 mediated targeted mutagenesis has been found to be successful in many crops and this feature can be used for crop improvement purposes as well (Junping et al., 2015).

\section{Designer Plant (Ideotyping)}

Crop ideotype involves all the morphological and physiological features that contribute to higher yield than currently existing crop cultivars. The concept of plant type was brought by Jennings in 1964 while the term 'ideotype' was introduces in 1968 by Donald. The ideal rice consists of 1 . Semi dwarf stature 2. High tillering ability 3. Short, erect, thick and highly angled leaves (Sharma et al., 2013). It has been long recognized that dry matter production and harvest index are the two focal points to be worked out for future breeding prospects with the cereals like rice intending to hit the ceiling in terms of yield. These physiological parameters were brought to limelight after recognition of ideotype as base for crop improvement. In ideotype breeding, we opt for each of the traits, consequently aiming for a description of model crop with traits of interest (Rasmusson, 1987). Yield is the function of harvest index and dry matter-yield can be increased via improvement of accumulated dry matter and increased harvest index. The harvest index can in fact be improved by increasing the sink size. Hence the rice crop ideotype breeding should be focused on large panicles, increased grain denseness, increased number of filled grains, leaf canopy, duration of growth and root characteristics. Ideotype breeding was more focused by researchers after the introduction of IR8 rice (a cross between Indonesian variety "Peta" and "Dee Gee Woo Gen" from Taiwan) which embarked the green revolution. Hence for engineering a rice with ideal characters, we should focus on overall characters viz photosynthetic characters, yield attributing characters and also the modification of plant morphology along with breeding. The rice crop would require three major ideotype changes for overall improvement i) heavy panicle ii) super high yielding plant type and iii) supper high yielding ideotype (Wu, 2008; Sharma et al., 2013). The overall ideotype building concept shall be centralized towards these goals:

- Maintaining moderate number of tillers (270-300 panicles per sq.m)

- Heavy panicles (weighing $5 \mathrm{~g}$ ) and panicles drooping at maturity

- $\quad$ Plant height nearly a meter and panicle height of 0.6 meter at maturity

- Attributes of top 3 leaves:

- Flag leaf of length $50 \mathrm{~cm}$ and length of other 2 leaves $55 \mathrm{~cm}$

- All three leaves shall be above the height of panicle

- A 55, 108- and 208-degree orientation of flag leaf, $1^{\text {st }}$ leaf and $2^{\text {nd }}$ leaf respectively

- Narrow and V shaped leaves with a width of $2 \mathrm{~cm}$ upon flattening

- Thick leaves with total specific weight of $55 \mathrm{~g}$ per sq.m (top 3 leaves)

- Leaf Area Index of top three leaves shall give a combined total of near 6.0

- $\quad$ Harvest Index shall be near to 0.55

\section{Heterosis Breeding and Apomictic Rice}

Hybrid rice have advantage over inbred rice in terms of yield varying from $10-15 \%$. It is evident that indica varieties are mostly used for development of the hybrids in IRRI but the magnitude of heterosis in fact depends in the diversity of two parents (Tollenaar, 1994). The greater the magnitude the higher is the heterosis. However, use of indica rice varieties has slowed down due to less gene flow among the varieties. Thus, the development of hybrid using indica and japonica variety is felt necessary It is considered that the improved varieties of japonica adapted in tropical region have been reported to have a higher heterosis. Development of hybrid rice is expected to enhance overall rice production in coming decades as different public and private sectors all over the worlds have made some progress (Yuan et al., 1989). The yield realization needs to be further boosted with a combination of heterosis and introgression of genes which provide tolerance to insect pests and diseases. Domain specific development of rice hybrid is absolute to develop a climate resilient rice hybrid. Hybrids for lowlands (rainfed) is felt necessary in South Asian countries. Development of suitable parental lines should be done to increase the degree of heterosis. On the other hand, molecular level understanding of hybrid development for plant modification can ensure a hybrid rice for future. Use of suitable technology provides with an opportunity to predict the best parents for hybrid development and hence opt for genetic improvement in yield and tolerance.

Despite the rapid advancement in development of hybrids, constraints involving adoption of hybrids, cost incurred, etc. seem to limit their usage. This challenges for development of apomictic rice hybrids. This allows the farmers to use the seeds from the crop harvested for the following year. Introduction of apomictic rice via introgression mutation and other genomic approaches is felt necessary along with a detailed study of diversity among species germplasm using some efficient techniques like Embryo-sac (ES) clearing, use of molecular markers and Flow cytometric Seed Screening (FCSS) (Kaushal et al., 2004). The use of such techniques will enable researchers to understand the role of traits and hence use them for breeding purposes. Apomictic rice development is a genuine need of farmers and its development with appropriate genes is necessary for wider adoption of hybrid rice (ICAR, 2013).

\section{Nitrogen Fixing Nutrient Rich Rice}

Use of fertilizers in rice has always been increasing after the Green Revolution, as the demand of fertilizers by the crop itself is high. Not only is the nutrient demand by hybrid rice a problem to small scale farmers but use of fertilizers has caused serious issues in the ecosystem as well. Contribution of fertilizers to the global carbon footprint of agriculture is ever increasing. Thus, engineering rice for the installment of a nitrogen fixing system is inevitable if we are looking for a sustainable production of rice.

The nitrogen fixation in rice will require nodule organogenesis and ultimately infection by nitrogen-fixing bacteria. We have to work out for maintaining a symbiosis between rice and the bacteria in order to develop a nodule and establish a mycorrhizal environment in the rice root system. A large number of diazotrophic microorganisms viz Alcaligenes, Azoarcus, Serratia marcesscens, Azorhizobium have been found to be associated with the 
roots of rice .Establishment of such system of rice need further genetic engineering and use of biotechnology for bacterial activity and nodule synthesis. With prediction of such huge rise in population, the demand for rice will definitely increase but we shall also look forward to making a rice that not only acts as a source of calorie but also provides protein and micronutrient. The rural and poor population suffering from malnutrition will need a rice that not only solves the problem of hunger but also prevents further malnutrition among the marginalized. The future rice demands biofortification which will help to combat against protein, calorie and micronutrient malnutrition (Bashir et al., 2013). All the conventional and recent technological approaches shall be directed towards utilization of genetic variation in order to create a rice with enhanced protein and micronutrient contents. The use of transgenic approaches also needs to be directed towards biofortification such that we can interfere with the current biosynthetic metabolism and direct end products towards synthesis of micronutrients, anti-oxidants, vitamins and protein (Bashir et al., 2013; ICAR, 2013).

\section{Exploitation of Nanotechnology and Precision Farming}

The use of modern technology has brought new achievements in different fields with flying colors while, in the agricultural sector, nanotechnology hasn't been exploited to the extent it shall be. Nanotechnology shall be focused primarily for early detection of nutrition deficiency, potential threats of insect pests and diseases, molecular level management of pests, a smart delivery system for increasing the input efficiency, etc. Agri-food nanotechnology is considered to be the next generation economic force in the field of agriculture. Nanotechnology can enhance the production of crops and its applications can be made for i) nanoformulations for application of chemicals and fertilizers ii) use of nano sensors for early warning and identification of diseases and pesticide residues iii) Use of nanotechnology for genetic manipulation iv). Diagnosis of plant diseases while precision farming techniques could further be of immense importance for crop improvement (Sekhon, 2014). Precision farming, on the other hand, is a systematic approach for management of soils and crops so as to prevent any sort of uncertainty with regards to decision making via in-depth understanding and management of spatial and temporal variation. Precision farming in rice can prove highly useful for significant improvement over crop yield, input use efficiency, profitability and reduced environmental impacts (Dobermann et al., 2004). With more recent advancement in site specific management viz GIS based irrigation management system, use of sensors, crop monitoring, crop models, etc., precision farming will act as a useful tool for taking decisions with respect to rice cultivation and management aspects (Dobermann et al., 2004; Rowshon and Amin, 2010).

\section{Conclusion}

The global food security is under great concern due to climate change, increasing global rice demands as well as the unpredictable impacts of post COVID-19 on cereal production. There have been promising approaches for designing a rice with enhanced photosynthetic pathway viz introduction of $\mathrm{C} 4$ traits. It is evident that establishing $\mathrm{C} 4$ system in rice is a multidimensional approach that not only focuses on a particular gene but rather a combination of genetic engineering, breeding and use of recent technological advancements. While conversion of rice to $\mathrm{C} 4$ rice ensures an efficient photosynthesis, other approaches also need to go parallelly to ensure a high productivity for designing the future rice. The combined approach will definitely help to design an ideal rice for next century but we also need to overcome some constraints in the way.

\section{References}

Agarie S, Tsuchida H, Ku M, Nomura M, Matsuoka M, Miyao Tokutomi M. 1998. High level expression of C, enzymes in transgenic rice plants. In G. Garab, Photosynthesis: mechanisms and effects Vol. 5, pp: 3425-3426. The Netherlands: Kluwer Academic.

Akita S. 1994. Eco-physiological aspect of raising the yield plateau of irrigated rice in the tropics. Breaking the yield barrier. Philippines: Philippines.

Anthem P. 2020. Risk of hunger pandemic as COVID-19 set to almost double acute hunger by end of 2020. World Food Program Insights. Retrieved from https://insight.wfp.org/ covid-19- will-almost-double-people-in-acute-hunger-byend-of-2020-59df0c4a8072

Badger MR, Andrews JT, Whitney SM, Ludwig M, Yellowless D, Leggat W, Price GD. 2011. The diversity and coevolution of Rubisco, plastids, pyrenoids, and chloroplast-based CO2concentrating mechanisms in algae. Canadian Journal of Botany, 76(6): 1052-1071.

Bairagi S, Mohanty S. 2017. Compliance Costs for Regulatory Approval of C4 Rice. Agriculture BioForum, 20(2): 84-93.

Bashir K, Takahashi R, Nakanishi H, Nishizawa NK. 2013. The road to micronutrient biofortification of rice: progress and prospects. Frontiers of Plant Science, 4, 15. doi:10.3389/ fpls.2013.00015

Burris R, Black C. 1976. CO2 metabolism and plant productivity. Baltimore: University Park Press.

Caemmerer V, Susanne Quick WP, Furbank TR. 2012. The development of $\mathrm{C} 4$ rice: Current progress and future challenges. Science, 336(6089): 1671-1672.

Cerling T. 1999. Paleorecords of C4 plants and ecosystems. In R. Sage, R. Monson Eds, C4 Plant Biology pp: 455-469. San Diego, California, USA: Academic Press.

Covshoff Sarah, Hibberd JM. 2012. Integrating C4 photosynthesis into C3 crops to increase yield potential. Current opinion in biotechnology, 23(2): 209-214.

Dawe D. 2000. The contribution of rice research to poverty alleviation. In J. Sheeshy, P. Mitchell, B. Hardy, Redesigning Rice Photosynthesis to Increase yield pp: 3-12. Philippines: IRRI.

Dawe D. 2000. The potential role of biological nitrogen fixation in meeting future demand for rice and fertilizer. In J. Ladha, P. Reddy Ed, Proceedings of the Third Working Group Meeting on Assessing Opportunities for Nitrogen Fixation in Rice pp: 1-9. Laguna, Philippines: IRRI.

Dobermann A, Blackmore S, Cook ES, Adamchuk IV. 2004. Precision Farming: Challenges and Future Directions. 4th International Crop Science Congress pp: 1-19. Brisbane, Austrailia: CDROM. Retrieved from www.cropscience. org.au

Ehleringer JR, Monson RK. 1993. Evolutionary and ecological aspects of photosynthetic pathway variation. Annu Rev Ecol Syst, 24: 411-439.

FAO. 2020. World food situation. FAO. Retrieved from http://www.fao.org/worldfoodsituation/csdb/en/

FAOSTAT. 2018, February 13. Retrieved from FAOSTAT Data: http://www.fao.org/faostat/en/\#data/QC 
Feldman A, Murchie E, Leung H, Baraoidan M, Coe R, Yu S.-M. 2014. Increasing Leaf Vein Density by Mutagenesis: Laying the Foundations for C4 Rice. PLOS ONE, 9(4).

Foley JA, DeFries R, Asner GP, Barford C, Bonan G, Carpenter SR. 2005. Global Consequences of Land Use. SCIENCE, 309(5734): 570-574.

Furbank R. 2011. Evolution of the C4 photosynthetic mechanism: are there really three $\mathrm{C} 4$ acid decarboxylation types? J Exp Bot, 62: 3103-3108.

Furbank RT, Quick PW, Sirault XR. 2015. Improving photosynthesis and yield potential in cereal crops by targeted genetic manipulation: Prospects, progress and challenges. Field Crops Research, 182: 19-29.

Furbank R, von Caemmerer S, Sheehy J, Edwards G. 2009. C4 rice: A challenge for plant phenomics. Funct. Plant Biol., 36: 845-856.

Gangurde S, Autade R, Akula D, More Y. 2016. C4 Rice: A Step Towards Evergreen Revolution. A Journal of Agriculture and Rural Development, 43(9): 25-26.

Gnanamanickam SS. 2009. Rice and its importance to human life.

Gowik U, Westhoff P. 2011. The Path from C3 to C4 Photosynthesis. American Society of Plant Biologists, 110: 1104.

Hatch M, Osmond C, Slatyer R. 1971. Photosynthesis and photorespiration (Vol. 125). New York: Wiley-Interscience.

Henry R. 2020. Innovation in Agriculture and Food Supply in Response to the COVID-19 Pandemic. Molecular Plant, 13: 1095-1097.

Hibberd JM, Sheehy JE, Langdale JA. 2008. Using C4 photosynthesis to increase the yield of rice-rationale and feasibility. Current opinion in plant biology, 11(2): 228-231.

ICAR. 2013. Vision 2050. Cuttack (Odisha), India: Central Rice Research Institute. Retrieved from www.cri.nic.in

Imaizumi N, Samejima M, Ishihara K. 1997. Characteristics of photosynthetic carbon metabolism of spikelets in rice. Photosynthesis and Respiration Research, 52: 75-82.

IRRI. 2012, December 4. Science of C4 Rice. Retrieved from http://photosynthome.irri.org/C4rice/index.php/component/c ontent/article/19-about/57-science-of-c4-rice

Jambor A, Czine P, Balogh P. 2020. The impact of the coronavirus on agriculture: first evidence based on global newspapers. Sustainability, 12: 4535.

Jennings P. 1964. Plant type as a rice breeding objective. Crop Sci., 35: 13-15.

Junping G, Wang G, Ma S, Xie X, Wu X, Zhang X, Qingyou 2015. CRISPR/Cas9-mediated targeted mutagenesis in Nicotiana tabacum. Plant Molecular Biology, 87: 99-110.

Kajala K, Covshoff S, Karki S, Woodfield H, Tolley B, Dionora M, Quick W. 2011. Strategies for engineering a two celled C4 photosynthetic pathway into rice. Journal of experimental botany, 62(9): 3001-3010.

Kaushal P, Malaviya D, Roy A. 2004. Prospects for breeding apomictic rice: A reassessment. Current Science, 87(3): 292-296.

Khan M, Maliga P. 1999. Fluorescent antibiotic resistance marker for tracking plastid transformation in higher plants. Natural Biotechnology, 17: 910-915.

Khush G. 2000. Strategies for increasing the yield potential of rice. In J. Sheehy P. Mitchell, B. Hardy, Redesigning Rice Photosynthesis to Increase Yield pp: 207-212. Philippines: IRRI.

Kishore G. 1994. Starch biosynthesis in plants: identification of ADP glucose pyro phosphorylase as a rate-limiting step. Breaking the yield barrier pp: 117-119. Manila, Philippines: IRRI.

$\mathrm{Ku}$ M, Agarie S, Nomura M. 1999. High-level expression of maize phosphoenol pyruvate carboxylase in transgenic rice plants. National Biotechnology, 17: 76-80.

$\mathrm{Ku}$ M, Monson R, Littlejohn R, Nakamoto HDBF, Edwards, G. 1983. Photosynthetic characteristic of C3-C4 intermediate Flaveria species: I. Leaf anatomy, photosynthetic responses to oxygen, carbon dioxide and activities of key enzymes in the C3 and C4 pathways. Plant physiology, 71: 944-948.
Leegood CR. 2002, April. C4 photosynthesis: principles of CO2 concentration and prospects for its introduction into $\mathrm{C} 3$ plants. Journal of Experimental Botany, 53(369): 581-590.

Legwood RC. 2013. Strategies for engineering C4 photosynthesis. Journal of Plant Physiology, 170(4): 378388.

Long SP, Marshall-Colon A, Zhu XG. 2015. Meeting the global food demand of the future by engineering crop photosynthesis and yield potential. Cell, 161: 56-66.

Long S, Zhu XG, Naidu S, Ort D. 2006. Can improvement in photosynthesis increase crop yields? Plant Cell Environment, 29: 315-330.

Long-ping Y. 2014. Development of Hybrid Rice to Ensure Food Security. Rice Science, 21(1): 1-2.

Matsuoka M, Furbank R, Fukayama H, Miyao M. 2001. Molecular engineering of C4 photosynthesis. Annu. Rev. Plant Physiol. Plant Mol. Biol., 52: 297-314.

Maurice SB, Dongha C, Xia Lit DMJ, Pintot M, Miyaol M, Matsuokas M. 2007. Introduction of genes encoding C4 photosynthesis enzymes into rice plants: physiological consequences. Rice biotechnology: Improving yield. stress tolerance and grain quality, 236: 100-116.

Mitchell P, Sheehy J. 2007. The Case for C4 Rice. In J. Sheeshy P. Mitchell, B. Hardy, Charting New Pathways to C4 Rice pp: 27-36. Los Banos, Manila, Philippines: IRRI.

Raines C. 2006. Transgenic approaches to manipulate the environmental responses of the C3 carbon fixation cycle. Plant Cell Environment, 29: 331-339.

Rasmusson D. 1987. An evaluation of ideotype breeding. Crop Science, 27: 1140-1146.

Rizal G, Karki S, Thakur V, Chatterjee J, Coe RA, Wanchana S, Quick, WP. 1999. Towards a C4 Rice. In S. Long, R. Sage, R. Monsoon (Eds.), C4 Plant Biology pp: 215-249. San Diego, CA, USA: Academic Press.

Rowshon MK, Amin MS. 2010. GIS- based irrigation water management for precision farming of rice. International Journal of Agriculture and Biology Engineering, 3(3): 27. doi: 10.3965

Sage R. 2004. The evolution of C4 photosynthesis. New Phytology, 1618: 341-370.

Sage R, Christin P, Edwards E. 2011. The C4 plant lineages of planet Earth. J Exp Bot, 62: 3155-3169.

Sekhon SB. 2014. Nanotechnology in agri-food production: an overview. Nanotechnology Science and Applications, 7: 3153.

Sharma D, Sanghera SG, Sahu P, Sahu P, Parikh M, Sharma B, Jena KB. 2013. Tailoring rice plants for sustainable yield through ideotype breeding and physiological interventions. African Journal of Agricultural Research, 8(40): 5004-5019. doi:10.5897/AJAR2013.7499

Sharwood RE, Ghannoum O, Whitney SM. 2016). Prospects for improving $\mathrm{CO} 2$ fixation in $\mathrm{C} 3$-crops through understanding C4-Rubisco biogenesis and catalytic diversity. Current opinion in plant biology., 31: 135-142.

Sheehy J, Dionora M, Mitchell P. 2001. Spikelet numbers, sink size and potential yield in rice. Field Crops Research, 71: 7785.

Sheehy J, Ferrer A, Mitchell P, Elmido-Mabilangan A, Pablico P, Dionora M. 2007. How the rice crop works and why it needs a new engine. In J. Sheehy, P. Mitchell, B. Hardy, Charting New Pathways to C4 Rice pp: 3-26. Los Banos, Philippines, Manila, Philippines: IRRI. Retrieved from irri@cgiar.org

Sofi P, Wani S. 2007. Prospects of nitrogen fixation in rice. Asian Journal of Plant Sciences, 6(1): 203-213.

Sowjanya BA, Narayana B, Shreyas S. 2019. Enhancement of Photosynthetic Efficiency of C3 Plants. International Journal of Current Microbiology and Applied Sciences, 775-786.

Tanksley S, Young N, Patterson A, Bonierbale M. 1989. RFLP mapping in plant breesing: new tools for an old science. Biotechnology, 7: 257-264. 
Tollenaar M. 1994. Yield potential of maize: impact of stress tolerance. Breaking the yield barrier pp: 103-109. Manila, Philippines: IRRI.

Torero M. 2020. Without food, there can be no exit from the pandemic. Nature, 580: 588-589.

UNDP. 2015. Transforming our world: The 2030 agenda for sustainable development. New York: United Nations. Retrieved from sustainabledevelopment.un.org

Vaughan D. 1994. The wild relatives of rice: a genetic resources handbook. Manila, Philippines: IRRI.

Wang L, Ma G, Wang H, Cheng C, Mu S, Quan W, Zhang Y. 2019. A draft genome assembly of halophyte Suaeda aralocaspica, a plant that performs $\mathrm{C} 4$ photosynthesis within individual cells. Giga Science, 8: 1-9.

Whitney S, Baldet P, Hudson, G, Andrew T. 2001. Rubiscos from non-green algae are expressed abundantly but not assembeled in tobacco cholorplasts. The Plant Journal, 1: 535-547.

Winzer T, Heineke D, Bauwe H. 2001. Growth and phenotype of potato plants expressing an antisense gene of P-protein of glycine decarboxylase under control of a promotor with preference for the mesophyll. Annals of Applied Biology, 138: 9-15.
Wu X. 2008. Prospects of developing hybrid rice with super high yield. Journal of Agronomy, 101(3): 688-689.

Xu R. 2016. Rapid improvement of grain weight via highly efficient CRISPR/Cas9-mediated multiplex genome editing in rice. Journal of Genetics and Genomics, 1-4. doi:http://dx.doi.org/10.1016/j.jgg.2016.07.003

Yamori W, Hikosaka K, Way AD. 2014. Temperature response of photosynthesis in $\mathrm{C} 3, \mathrm{C} 4$, and CAMplants: temperature acclimation and temperature adaptation. Photosynthesis Research, 119: 101-117. doi:10.1007/s11120-013-9874-6

Yeo M, Yeo A, Flowers T. 1994. Photosynthesis and photorespiration in the genus Oryza. Journal of Experimental Botany, 45: 553-560.

Yoshida S. 1973. Effects of CO2 enrichment at different stages of panicle development on yield components and yield of rice (Oryza sativa L.). Journal of Soil Science and Plant Nutrition, 19: 311-316.

Yuan L, Virmani S, Mao C. 1989. Hybrid rice: achievements and future outlook. Progress in irrigated rice research pp: 219235. Philippines: IRRI 